\title{
POTENCIAL DE PRODUÇÃO DE GÁS METANO E DIÓXIDO DE CARBONO IN VITRO DOS INGREDIENTES UTILIZADOS EM DIETAS PARA OVINOS
}

\author{
Eliane da Silva Morgado ${ }^{1}$, JANE Maria Bertocco Ezequiel ${ }^{2}$, ANTÔNIO CARlos Homen \\ JÚNIOR $^{3}$, LEANDRO GALZERANO ${ }^{4}$
}

\author{
${ }^{1}$ Pós-Doutoranda da Universidade Estadual Paulista, Jaboticabal, SP, Brasil. eliane_morgado@ @otmail.com \\ ${ }^{2}$ Professora Doutora da Universidade Estadual Paulista, Jaboticabal, SP, Brasil. \\ ${ }^{3}$ Pós-Graduando da Universidade Estadual Paulista, Jaboticabal, SP, Brasil. \\ ${ }^{4}$ Pós-Doutorando da Universidade Federal de Uberlândia, Uberlândia, MG, Brasil.
}

RESUMO

\begin{abstract}
Objetivou-se avaliar o potencial de produção dos gases $\mathrm{CH}_{4}$ e $\mathrm{CO}_{2}$ in vitro dos ingredientes casca de soja, farelo de girassol, milho, polpa cítrica e silagem de milho. Quatro ovinos canulados no rúmen foram alimentados com dietas contendo os ingredientes avaliados na proporção volumoso:concentrado de 40:60. Os gases produzidos na incubação das amostras em líquido ruminal foram mensurados pela injeção em cromatógrafo gasoso equipado com detector de ionização de chama. $\mathrm{O}$ delineamento utilizado foi o inteiramente ao acaso em medidas repetidas no tempo, com três repetições para cada
\end{abstract}

alimento avaliado em quatro diferentes períodos. Nas condições experimentais deste trabalho, foram verificados diferentes potenciais para produção de gases entre os ingredientes. A polpa cítrica foi o ingrediente de maior potencial de produção de $\mathrm{CO}_{2}$. A silagem de milho e casca de soja foram os ingredientes de maior potencial e a polpa cítrica e o farelo de girassol os de menor potencial para produção de $\mathrm{CH}_{4}$ em relação à matéria seca degradada, podendo ser considerados, entre os ingredientes avaliados, os de menores impactos ao ambiente.

PALAVRAS-CHAVE: Alimentos; $\mathrm{CH}_{4} ; \mathrm{CO}_{2}$; degradação; ruminantes.

\section{POTENTIAL OF METHANE AND CARBON DIOXIDE IN VITRO PRODUCTION OF INGREDIENTS USED IN DIETS FOR SHEEP}

\section{ABSTRACT}

This study aimed to evaluate the potential of $\mathrm{CH}_{4}$ and $\mathrm{CO}_{2}$ in vitro production of soybean hulls, sunflower meal, corn, citrus pulp and corn silage. Four rumencannulated sheep were fed diets containing the evaluated ingredients at 40:60 forage:concentrate ratio. The gases produced by samples incubation were measured by injection into a gas chromatograph equipped with flame ionization detector. The experimental design was completely randomized with repeated measures, with three replicates for each evaluated food at four different periods. Under the experimental conditions, we verified different potential gas production among the ingredients. The citrus pulp meal was the ingredient with the greatest potential for $\mathrm{CO}_{2}$ production. Corn silage and soybean hulls showed the greatest potential while citrus pulp and sunflower meal showed the least potential for $\mathrm{CH}_{4}$ production, when expressed in $\mathrm{mL} / \mathrm{g}$ of degraded dry matter; therefore, they can be considered, among the evaluated ingredients, those with the lowest environmental impact.

KEYWORDS: $\mathrm{CH}_{4}$; $\mathrm{CO}_{2}$; degradation; feed; ruminant. 


\section{INTRODUÇÃO}

A fermentação dos alimentos no rúmen é uma grande fonte de produção de $\mathrm{CH}_{4}$, pois este é um subproduto da fermentação anaeróbica (MOSS et al., 2000; BEAUCHEMIN et al., 2008) e representa perdas de 2 a $12 \%$ da energia consumida dos alimentos pelos ruminantes (JOHNSON \& JOHNSON, 2005), além de contribuir para o aquecimento global.

A emissão de $\mathrm{CH}_{4}$ pelos ruminantes depende de vários fatores como espécie animal, composição e quantidade de concentrado na dieta (SEJIAN et al., 2011), nível de consumo, tipo de carboidratos na dieta, processamento das rações, adição de lipídios ou ionóforos na dieta e alteração da microflora ruminal (JOHNSON \& JOHNSON, 2005).

As diferenças na composição nutricional dos alimentos podem acarretar padrões fermentativos distintos, resultando em diferentes proporções dos produtos finais da fermentação como os ácidos graxos acético, propiônico e butírico, que representam uma importante fonte de energia para o metabolismo dos ruminantes. Juntamente com esses processos fermentativos há produção de $\mathrm{CO}_{2}$ e $\mathrm{CH}_{4}$, em maior ou menor quantidade, dependendo da proporção individual dos ácidos produzidos que é influenciada pela composição da matéria orgânica das dietas, principalmente pela natureza e taxa de fermentação dos carboidratos (MOSS et al., 2000).

Devido às diferenças nutricionais entre os ingredientes e consequentemente as diferenças nas taxas de fermentação, objetivou-se avaliar o

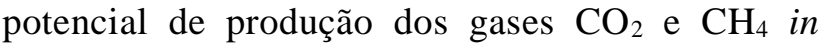
vitro dos ingredientes casca de soja, farelo de girassol, milho, polpa cítrica e silagem de milho utilizados na formulação de dietas para ovinos.

\section{MATERIAL E MÉTODOS}

$\mathrm{O}$ experimento foi conduzido na Unidade Animal de Estudos Digestivos e Metabólicos pertencente ao Departamento de Zootecnia da Faculdade de Ciências Agrárias e Veterinárias, Unesp, Campus de Jaboticabal.

Foram utilizados quatro ovinos $1 / 2$ Santa Inês $1 / 2$ Dorper com peso corporal médio de $47,3 \mathrm{~kg}$, canulados no rúmen, alojados em baias com piso cimentado com comedouros e bebedouros individuais, alimentados duas vezes por dia com dieta contendo $40 \%$ de volumoso e $60 \%$ de concentrado.

As amostras dos ingredientes casca de soja, farelo de girassol, milho, polpa cítrica e silagem de milho, pré-seca em estufa a $55^{\circ} \mathrm{C}$ por 72 horas, foram moídas em moinho de facas, com peneira com crivo de $1 \mathrm{~mm}$ para as determinações dos teores de matéria seca (MS), cinzas e extrato etéreo (EE), de acordo com AOAC (1995), fibra em detergente neutro (FDN) segundo VAN SOEST et al. (1991), fibra em detergente ácido (FDA) segundo VAN SOEST \& ROBERTSON (1985), sequencialmente à FDN, fibra solúvel em detergente neutro (FSDN), quantificada conforme metodologia descrita por HALL (2000), e amido estimado segundo método descrito por HENDRIX (1993), para a extração e para a leitura colorimétrica utilizou-se o ácido dinitrosalisílico (DNSA), segundo metodologia descrita por MILLER (1959). A composição químicobromatológica dos ingredientes avaliados pode ser verificada na Tabela 1.

Tabela 1. Composição químico-bromatológica dos ingredientes

\begin{tabular}{lcccccccc}
\hline \multirow{2}{*}{ Ingrediente } & \multicolumn{8}{c}{ Nutriente $(\%)$} \\
\cline { 2 - 9 } & MS & PB & MM & EE & FDN & FDA & FSDN & Amido \\
\hline Silagem de milho & 40,00 & 8,30 & 3,93 & 3,10 & 46,00 & 27,79 & 4,9 & 37,36 \\
Milho & 89,43 & 9,72 & 1,29 & 4,36 & 10,51 & 2,83 & 6,07 & 68,17 \\
Polpa cítrica & 88,27 & 7,40 & 7,18 & 2,20 & 26,36 & 22,08 & 49,81 & 7,56 \\
Casca de soja & 89,45 & 11,29 & 4,13 & 1,42 & 73,11 & 55,57 & 7,17 & 6,05 \\
Farelo de girassol & 89,67 & 29,19 & 4,87 & 1,19 & 52,97 & 44,87 & 3,48 & 4,08 \\
\hline
\end{tabular}

MS = matéria seca; $\mathrm{PB}=$ proteína bruta; $\mathrm{MM}$ = matéria mineral; $\mathrm{EE}=$ extrato etéreo; FDN = fibra em detergente neutro; FDA $=$ fibra em detergente ácido; FSDN = fibra solúvel em detergente neutro. 
Para avaliação da taxa de desaparecimento ruminal dos ingredientes, foram confeccionados sacos de nylon $100 \%$ poliamida, não resinados, com porosidade de $50 \mu \mathrm{m}$, medindo $14 \mathrm{~cm}$ de comprimento por $7 \mathrm{~cm}$ de largura, selados em seladora automática. Os sacos receberam aproximadamente $4 \mathrm{~g}$ de amostra, mantendo relação de $20 \mathrm{mg}$ matéria seca do alimento por centímetro quadrado de tecido, conforme proposto por NOCEK (1988) como ideal para avaliação da degradabilidade in situ. Os sacos foram incubados no rúmen dos ovinos por 12 horas, para que fossem feitas comparações com a produção de gases. Após esse período, os sacos forma retirados do rúmen e imersos em água fria com gelo por 30 minutos para cessar a atividade microbiana, sendo em seguida lavados em água corrente até a observação da água limpa e sem sólidos. Os sacos com os resíduos foram secos em estufa de circulação forçada de ar a $55^{\circ} \mathrm{C}$ por 72 horas e pesados. A taxa de desaparecimento da matéria seca foi calculada pela fórmula:

$$
\operatorname{DMS}(\%)=\left(1-\frac{P S I-P S V}{P S A-P S V}\right) \times 100
$$

em que DMS\% é o porcentual de degradabilidade da MS; PSI é o peso do saco depois da incubação ruminal; PSV é o peso do saco vazio e PSA é o peso do saco antes da incubação ruminal. $\mathrm{O}$ cálculo do percentual de degradabilidade de cada nutriente foi efetuado por meio da fórmula acima e as diferenças (PSI - PSV) e (PSA - PSV) foram multiplicadas pelas respectivas porcentagens de cada nutriente. Os teores dos nutrientes dos resíduos foram obtidos utilizando-se as mesmas técnicas para a análise da composição químico-bromatológica dos ingredientes.

As determinações das produções dos gases $\mathrm{CH}_{4}$ e $\mathrm{CO}_{2}$ foram repetidas durante quatro períodos (dias) para cada ingrediente, utilizando-se a metodologia proposta por GASTALDI (2003) adaptada para ovinos que consiste em três etapas. A primeira etapa consiste no preparo da amostra: antes da alimentação foram coletados aproximadamente $500 \mathrm{~mL}$ do conteúdo ruminal de cada animal, filtrados em tecido de náilon $(100 \mu \mathrm{m})$ e misturados, formando, assim, um ambiente homogêneo. Em erlenmeyer com capacidade de $250 \mathrm{~mL}$, foram adicionados $150 \mathrm{~mL}$ do líquido ruminal contendo 2,1 g de amostras de cada ingrediente previamente adicionada para servir como substrato para a fermentação microbiana, mantendo-se a relação de $1,25 \mathrm{~g}$ de $\mathrm{MS} / 100 \mathrm{~mL}$ de líquido ruminal, sendo realizadas também a incubação de três bancos, contendo apenas o líquido ruminal, sem amostra de ingrediente. A segunda etapa é a de produção e armazenamento dos gases: os erlenmeyer contendo as amostras e o líquido ruminal foram mantidos por 12 horas em banho-maria à temperatura de $39^{\circ} \mathrm{C}$, em ambiente escuro, e os gases produzidos foram armazenados em um recipiente plástico tipo pet adaptado ao sistema, com volume interno de $600 \mathrm{~mL}$. A terceira etapa é a da análise qualitativa e quantitativa do gás produzido: foi colhida uma alíquota diretamente dos recipientes plásticos com o auxílio de uma seringa plástica com válvula, com capacidade de $1,0 \mathrm{~mL}$, sendo imediatamente injetada em cromatógrafo gasoso Trace GC Ultra da Thermo Scientific, equipado com detector de ionização de chama, utilizando-se o argônio como gás de arraste com fluxo de $25 \mathrm{~mL}$ por minuto e a temperatura do forno de $70^{\circ} \mathrm{C}$. A calibração foi realizada com uma mistura padrão de gases $\mathrm{CH}_{4}$ e $\mathrm{CO}_{2}$. As áreas dos picos foram integradas utilizando-se o software Chromquest 5.0.

A quantidade total de gás produzido foi mensurada pela determinação do volume ocupado pelo gás produzido dentro dos recipientes plásticos após 12 horas de fermentação. Esse tempo foi considerado devido à frequência de alimentação a que os animais experimentais foram submetidos de duas refeições diárias, com intervalo de 12 horas entre elas.

Para as avaliações e comparações da produção de $\mathrm{CH}_{4}$ e $\mathrm{CO}_{2}$ entre os ingredientes, foi utilizado o delineamento inteiramente casualizado em medidas repetidas no tempo, com três repetições para cada alimento avaliado (tratamentos) em quatro diferentes períodos (tempos), utilizando-se modelos mistos do SAS (2008) (Statistical Analysis System). A comparação das médias foi feita pelo teste de Tukey, considerando-se o nível de significância de $5 \%$.

\section{RESULTADOS E DISCUSSÃO}

Os valores médios das taxas de desaparecimento da MS, PB, FDN e amido após 12 horas de incubação in situ podem ser verificados na Tabela 2.

As altas taxas de degradação da PB, FDN e amido da polpa cítrica, juntamente com o alto teor de fibra solúvel em detergente neutro $(49,81 \%)$ que é rapida e extensivamente degradada pelos microrganismos ruminais (HALL, 2000), podem explicar a maior taxa de degradação da MS deste ingrediente após 12 horas de fermentação. Segundo HALL (2000), 85\% da FDN da polpa cítrica é fermentada em 24 horas, com semelhante taxa de fermentação da fibra solúvel em detergente neutro (FSDN), constituída por frutosanas, $\beta$-glucanas e substâncias pécticas. 
Tabela 2. Desaparecimento (\%) da matéria seca, proteína bruta, fibra em detergente neutro e amido dos ingredientes após doze horas de incubação in situ

\begin{tabular}{lccccc}
\hline \multirow{2}{*}{ Nutriente } & \multicolumn{5}{c}{ Ingrediente } \\
\cline { 2 - 6 } & $\begin{array}{c}\text { Polpa } \\
\text { cítrica }\end{array}$ & Milho & $\begin{array}{c}\text { Casca } \\
\text { de soja }\end{array}$ & $\begin{array}{c}\text { Farelo } \\
\text { de girassol }\end{array}$ & $\begin{array}{c}\text { Silagem } \\
\text { de milho }\end{array}$ \\
\hline Matéria seca & 70,36 & 40,84 & 35,60 & 58,02 & 45,28 \\
Proteína bruta & 71,07 & 46,97 & 51,26 & 86,99 & 69,42 \\
Fibra em detergente neutro & 50,49 & 62,67 & 28,52 & 35,17 & 20,16 \\
Amido & 78,96 & 44,18 & 69,62 & 77,71 & 90,71 \\
\hline
\end{tabular}

A degradação do amido foi variável entre os ingredientes avaliados com praticamente completa degradação do amido da silagem de milho após 12 horas de incubação e a menor degradação foi verificada para o milho. Segundo OFFER et al. (2003), a degradabilidade da silagem de milho é afetada pelo genótipo e maturidade da planta, sendo influenciada grandemente pelo teor de matéria seca da silagem. ROONEY \& PFLUGFELDER (1986) inferiram que a digestibilidade do amido dos alimentos pode sofrer variações, dependendo de fatores como relação amilose/amilopectina na estrutura do amido, tipo de endosperma (córneo ou farináceo), tipo de grão de cereal, método de processamento e forma física utilizada.

$\mathrm{O}$ teor de nutrientes do farelo de girassol varia segundo o processo da extração do óleo e da quantidade de casca presente, o que lhe confere alto teor de fibra. $\mathrm{O}$ alto teor de proteína bruta é a principal referência para o emprego desse farelo na alimentação animal e, como foi verificado, a PB é rapidamente degradada no rúmen $(86,99 \%$ com 12 horas de incubação), o que pode explicar a alta degradação da matéria seca deste ingrediente.

$\mathrm{O}$ alto percentual de FDN $(73,11 \%)$ da casca de soja e a menor degradação deste componente em comparação à polpa cítrica, ao milho e ao farelo de girassol no período de incubação de 12 horas podem ter levado à menor degradação da MS da casca de soja no tempo de incubação estabelecido. Segundo BACH et al. (1999), a casca de soja é um ingrediente com alto teor de FDN altamente digestível, com alto teor de celulose e baixo teor de lignina, fazendo com que seja altamente degradável no rúmen com elevada produção de ácidos graxos de cadeia curta, em razão da elevada fermentação da fibra no rúmen. A baixa degradação da FDN da silagem de milho pode ser atribuída ao reduzido tempo de incubação de 12 horas, uma vez que a fração fibrosa dos alimentos possui lenta taxa de fermentação ruminal.

Os valores médios do potencial de produção dos gases $\mathrm{CH}_{4}, \mathrm{CO}_{2}$ e volume total de gás dos ingredientes podem ser observados na Tabela 3 .

Tabela 3. Produção de gás in vitro dos ingredientes avaliados

\begin{tabular}{lcccccc}
\hline Variável & \multicolumn{5}{c}{ Ingrediente } & \multirow{2}{*}{ Pr $>\mathrm{F}$} \\
\cline { 2 - 5 } & Polpa & Milho & Casca & Farelo & Silagem & 0,05 \\
$\mathrm{CH}_{4}$ (mL/g MS incubada) & 10,47 & 8,38 & 8,69 & 9,66 & 11,03 & 0.06 \\
$\mathrm{CO}_{2}$ (mL/g MS incubada) & $43,31 \mathrm{a}$ & $35,90 \mathrm{~b}$ & $29,79 \mathrm{c}$ & $37,14 \mathrm{~b}$ & $31,88 \mathrm{bc}$ & $<0,01$ \\
Total (mL/g MS incubada) & $50,07 \mathrm{a}$ & $45,30 \mathrm{bc}$ & $38,27 \mathrm{c}$ & $49,50 \mathrm{ab}$ & $45,72 \mathrm{bc}$ & $<0,01$ \\
$\mathrm{CH}_{4}$ (mL/g MS degradada) & $14,88 \mathrm{c}$ & $20,53 \mathrm{~b}$ & $24,41 \mathrm{a}$ & $16,66 \mathrm{c}$ & $24,36 \mathrm{a}$ & $<0,01$ \\
\hline
\end{tabular}

$\mathrm{Pr}>\mathrm{F}=$ Efeito dos tratamentos. Médias seguidas pela mesma letra, na linha, não diferem entre si pelo Teste de Tukey (p>0,05).

Não foram observadas diferenças para a produção de $\mathrm{CH}_{4}$, expressa em $\mathrm{mL} / \mathrm{g}$ MS incubada, entre os ingredientes avaliados. Porém, quando expressa em $\mathrm{mL} / \mathrm{g}$ de MS degradada, a silagem de milho e a casca de soja foram os ingredientes de maior potencial para produção de $\mathrm{CH}_{4}$, enquanto a polpa cítrica e o farelo de girassol os de menor potencial. LEE et al. (2003) avaliaram a produção de
$\mathrm{CH}_{4}$ in vitro de diversos ingredientes em 24 horas de incubação e verificaram que a casca de soja foi o ingrediente de maior produção de metano entre os farelos e cascas dos subprodutos avaliados. Esses autores inferiram que alimentos com alto teor de proteína bruta tendem a produzir menor quantidade de metano, pois $\mathrm{o} \mathrm{NH}_{4}$ resultante da degradação de fontes proteicas como farelo de oleaginosas podem 
combinar com o $\mathrm{CO}_{2}$ que é o substrato para a produção de $\mathrm{CH}_{4}$, resultando em menor produção, o que pode explicar a baixa produção de metano para o farelo de girassol.

Potencial médio para produçãode $\mathrm{CH}_{4} / \mathrm{g}$ de matéria seca fermentada, entre os ingredientes avaliados, foi verificado para o milho, pois a produção foi superior à polpa cítrica e ao farelo de girassol e inferior à silagem de milho e à casca de soja. Segundo MOSS et al. (2000), altos teores de amido nas dietas favorecem a produção de propionato e diminui a produção de $\mathrm{CH}_{4} /$ matéria orgânica fermentada no rúmen, pois bactérias que fermentam o amido podem competir com as metanogênicas pelo hidrogênio livre para a produção de propionato.

Foi observada correlação negativa $(-0,9)$ entre a degradação da MS e a produção de $\mathrm{CH}_{4}$ em $\mathrm{mL} / \mathrm{g}$ de MS degradada (Tabela 4), explicando a menor produção de $\mathrm{CH}_{4} \mathrm{em} \mathrm{mL} / \mathrm{g}$ de $\mathrm{MS}$ degradada para a polpa cítrica e o farelo de girassol que obtiveram maior degradação da matéria seca entre os ingredientes avaliados no tempo de incubação de 12 horas.

Tabela 4. Coeficiente de correlação (r) entre a composição nutricional e degradação dos nutrientes dos alimentos e a produção de gases in vitro

\begin{tabular}{lcccc}
\hline & $\mathrm{CH}_{4}(\mathrm{~mL})$ & $\mathrm{CO}_{2}(\mathrm{~mL})$ & Total $(\mathrm{mL})$ & $\mathrm{CH}_{4}(\mathrm{~mL} / \mathrm{g}$ MS degradada $)$ \\
\hline MO & $-0,84 * *$ & 0,21 & $-0,17$ & $-0,47$ \\
PB & $-0,07$ & 0,18 & 0,20 & $-0,35$ \\
Amido & $-0,28$ & $-0,28$ & 0,26 & 0,31 \\
FDN & 0,19 & $-0,48$ & $-0,37$ & 0,43 \\
CNF & $-0,17$ & 0,31 & 0,21 & $-0,23$ \\
FSDN & 0,19 & 0,74 & 0,59 & $-0,64$ \\
Degradação MS & 0,40 & $0,97 *$ & $0,94^{*}$ & $-0,90^{*}$ \\
Degradação PB & 0,63 & 0,61 & 0,34 & $-0,55$ \\
Degradação FDN & $-0,82^{* *}$ & 0,30 & $-0,10$ & $-0,48$ \\
\hline
\end{tabular}

$* \mathrm{p}<0,05 ; * * 0,05>\mathrm{p}<0,10$

A alta correlação positiva entre a degradação da MS e a produção total de gás e entre a degradação da MS e a produção de $\mathrm{CO}_{2}$ pode explicar o maior potencial de produção total de gás e $\mathrm{CO}_{2}$ da polpa cítrica e o menor potencial para a casca de soja, que apresentaram maior e menor degradação da matéria seca, respectivamente.

Segundo SANTOSO et al. (2009), o alto teor de FDN dos alimentos está relacionado com a alta produção de $\mathrm{CH}_{4}$, devido à alta correlação positiva observada entre a produção de metano e o teor de FDN dos alimentos, em 24 horas de incubação. MOSS et al. (2000) verificaram correlação positiva entre a produção de $\mathrm{CH}_{4} / \mathrm{g} \mathrm{MO}$ degradada e o teor de FDN da dieta em 24 horas de incubação. No presente estudo não foi verificada correlação entre o teor de FDN dos ingredientes e a produção de $\mathrm{CH}_{4}$, o que pode ser explicado pelo limitado tempo de incubação de 12 horas, que proporcionou baixa taxa de fermentação da FDN dos alimentos, uma vez que a FDN é a fração lentamente degradável. Os ingredientes com alto teor de fibra, como a casca de soja e a silagem de milho, apresentaram as menores taxas de desaparecimento da FDN, esses ingredientes apresentaram também maiores potenciais para a produção de $\mathrm{CH}_{4} / \mathrm{g}$ de $\mathrm{MS}$ degradada em comparação aos ingredientes com alta taxa de desaparecimento da FDN, como a polpa cítrica e o milho que foram os ingredientes de maior degradação da FDN, concordando com os resultados obtidos por PEREIRA et al. (2006) em avaliação com bovinos em 12 horas de fermentação in vitro. Segundo ALUWONG et al. (2011), quanto maior a digestibilidade dos alimentos menor será o tempo de permanência do alimento no rúmen e menor será a conversão de $\quad \mathrm{CO}_{2}$ a $\quad \mathrm{CH}_{4}$ pelas arqueias metanogênicas que utilizam o $\mathrm{H}_{2}$ para reduzir o $\mathrm{CO}_{2}$.

\section{CONCLUSÕES}

Os diferentes potenciais para produção de $\mathrm{CH}_{4}$ e $\mathrm{CO}_{2}$ estão relacionados com a composição bromatológica dos alimentos, em que ingredientes rapidamente fermentáveis tendem a produzir menor quantidade de $\mathrm{CH}_{4} / \mathrm{g}$ de matéria seca fermentada em comparação aos ingredientes com maior teor de fibra, podendo ser considerados na formulação de dietas visando o menor impacto ao ambiente.

\section{REFERÊNCIAS}

ALUWONG, T.; WUYEP, P.A.; ALLAM, L. Livestockenvironment interactions: Methane emissions from ruminants. African Journal of Biotechnology, v.10, n.8, 
p. 1265-1269, 2011.

ASSOCIATION OF OFFICIAL ANALYTICAL CHEMISTS - AOAC. Official methods of analysis. 16 ed., Washington D.C., 1995. 1094p.

BACH, A.; YOON, I.K.; STERN, M.D.; JUNG, H.G.; CHESTER-JONES, H. Effects of type of carbohydrate supplementation to lush pasture on microbial fermentation in continuous culture. Journal of Dairy Science, v.82, n.1, p.153-160, 1999.

BEAUCHEMIN, K.A.; KREUZER, M.; O'MARA, F.; MCALLISTER, T.A. Nutritional management for enteric methane abatement: A review. Australian Journal of Experimental Agriculture, v.48, p.21-27, 2008.

GASTALDI, K.A. Produção «in vitro» de metano, dióxido de carbono e oxigênio utilizando liquido ruminal de bovinos alimentados com diferentes rações. 2003.104 f. Tese (Doutorado em Zootecnia). Faculdade de Ciências Agrárias e Veterinárias, Universidade Estadual Paulista, Jaboticabal, 2003. Disponível em: http://www.athena.biblioteca.unesp.br/F/U1H19M59C3B GPLJKQ929V8YHQ1MRXE9AJ9S4R6RIGHPKYR1TH $\mathrm{R}-13568$ ? func $=$ short -0 b\&set number $=000959$ \&request $=$ Gastaldi $\% 2 C$

GETACHEW, G.; DEPETERS, E.J.; ROBINSON, P.H.; FADEL, J.G. Use of an in vitro rumen gas production technique to evaluate microbial fermentation of ruminant feeds and its impact on fermentation products. Animal Feed Science and Technology, v.123, n.124, p.547-559. 2005.

HALL, M.B. Neutral detergent-soluble carbohydrates nutritional relevance and analysis. Florida: University of Florida, 2000. 42 p. (Bulletin, 339).

HENDRIX, D.L. Rapid extration and analysis of nonstructural carboydrates in plant tissues. Crop Science, v.33, n.6, p.1306-1311, 1993.

JOHNSON, K.A.; JOHNSON, D.E. Methane emissions from cattle. Journal of Animal Science, v. 73, n.8, p.2483-2492, 1995.

LEE, H.J., LEE, S.C., KIM, J.D., OH, Y.G., KIM, B.K., KIM, C.W., KIM, K.J. Methane production potential of feed ingredients as measured by in vitro gas test. Asian-
Australasian Journal of Animal Science, v.16, n.8, p.1143-1150. 2003.

MILLER, G.L. Use of dinitrosalicylic acid reagent for determination of reducing sugar. Analytical Chemistry, v.31, n.3, p.426-428. 1959.

MOSS, A. R.; JOUANY, J. P.; NEWBOLD, C. J. Methane production by ruminants: its contribution to global warming. Annales de Zootechnie, v.49, p.231253, 2000.

OFFNER, A.; BACH, A.; SAUVANT, D. Quantitative review of in situ starch degradation in the rumen. Animal Feed Science and Technology, v.106, p.81-93, 2003.

PEREIRA, E.M.O.; EZEQUIEL, J.M.; BIAGIOLI, B.; FEITOSA, J. Determinação in vitro do potencial de produção de metano e dióxido de carbono de líquido ruminal proveniente de bovinos de diferentes categorias. Archivos Latinoamericano Produção Animal. v.14, n.4, p.120-127. 2006.

ROONEY, L.W.; PFLUGFELDER, R.L. Factors affecting starch digestibility with special emphasis on sorghum and corn. Journal of Animal Science, v.63, n.5, p.1607-1623, 1986.

SANTOSO, B.; HARIADI, B.T. Evaluation of nutritive value and in vitro methane production of feedstuffs from agricultural and food industry by-products. Journal of the Indonesian Tropical Animal Agriculture, v.34, p.189195, 2009.

SAS. 2008. SAS/STAT 9.2 User's Guide. SAS Institute Inc, Cary, NC.

SEJIAN, V.; LAL, R.; LAKRITZ, J.; EZEJI, T. Measurement and prediction of enteric methane emission. International Journal Biometeorology, v.55, n.1, p.116, 2011.

VAN SOEST, P.J.; ROBERTSON, J.P.; LEWIS, B.A. Methods for dietary fiber, neutral detergent fiber, and nonstarch polysaccharides in relation to animal nutrition. Journal of Dairy Science, v.74, n.10, p.3583-3597, 1991.

VAN SOEST, P.J.; ROBERTSON, J.B. Analysis of forages and fibrous foods. AS 613 Manual, Department of Animal Science, Cornell University, Ithaca, NY, 1985. 202p. 